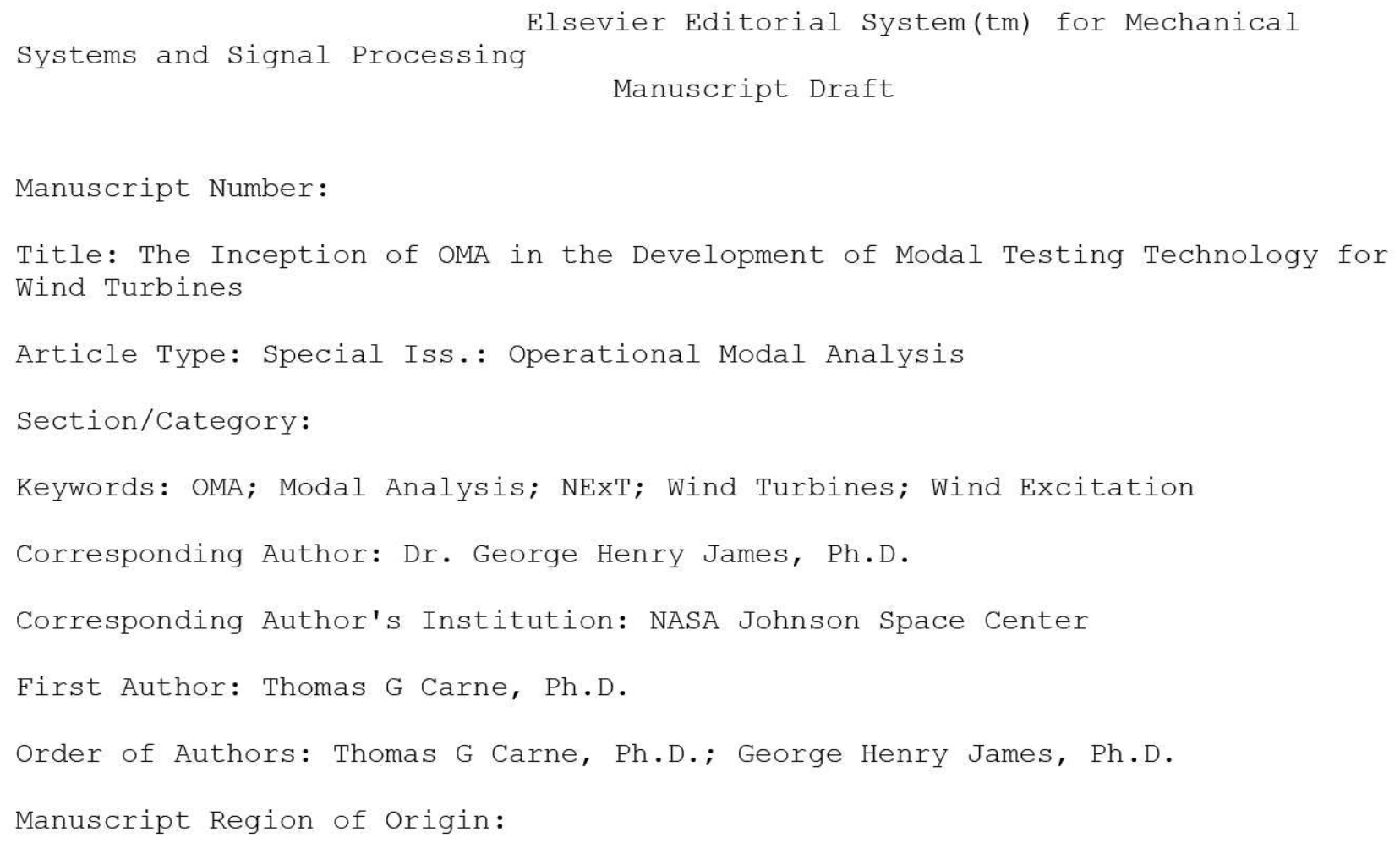


NASA Johnson Space Center

Mail Code ES6

2101 NASA Parkway

Houston, TX 77058

281-483-5550

george.h.james@nasa.gov

June 9, 2008

Mechanical Systems and Signal Processing

Elsevier Customer Service Department

6277 Sea Harbor Drive

Orlando, FL 32887-4800

Dear MSSP Editor:

Please consider the article entitled "The Inception of OMA in the Development of Modal Testing Technology for Wind Turbines" in the upcoming Operational Modal Analysis issue of Mechanical Systems and Signal Processing. The first author is Thomas G. Carne of Sandia National Laboratories and the Co-Author is George H. James of NASA Johnson Space Center. This paper contains the text from the keynote address by the same authors at the 2007 International Modal Analysis Conference.

Your consideration of this article is appreciated.

Sincerely,

George H. James III, Ph.D. 


\title{
The Inception of OMA in the Development of Modal Testing Technology for Wind Turbines
}

\author{
Thomas G. Carne ${ }^{1}$ \& George H. James III
}

\begin{abstract}
Wind turbines are immense, flexible structures with aerodynamic forces acting on the rotating blades at harmonics of the turbine rotational frequency, which are comparable to the modal frequencies of the structure. Predicting and experimentally measuring the modal frequencies of wind turbines has been important to their successful design and operation. Performing modal tests on wind turbine structures over 100 meters tall is a substantial challenge, which has inspired innovative developments in modal test technology. For wind turbines, a further complication is that the modal frequencies are dependent on the turbine rotation speed. The history and development of a new technique for acquiring the modal parameters using output-only response data, called the Natural Excitation Technique (NExT), will be reviewed, showing historical tests and techniques. The initial attempts at output-only modal testing began in the late 1980's with the development of NExT in the 1990's. NExT was a predecessor to OMA, developed to overcome these challenges of testing immense structures excited with environmental inputs. We will trace the difficulties and successes of wind turbine modal testing from 1982 to the present.
\end{abstract}

Keywords: OMA, Modal Analysis, NExT, Wind Turbines, Wind Excitation

\footnotetext{
${ }^{1}$ Sandia National Laboratories, M/S 0557, Albuquerque, NM, 87185 USA

Corresponding author. Tel.: 505-844-3266,E-mail address: tgcarne@sandia.gov

${ }^{2}$ NASA-Houston, JSC-ES6, Houston, TX, USA, Tel: 281-483-5550, E-mail address: george.h.james@NASA.gov
} 


\section{Introduction}

Windmills or wind turbines have existed and provided mechanical power for over a thousand years. The technology has obviously undergone tremendous improvements, particularly in the twentieth century. The modern era of large wind turbines for generating $\mathrm{AC}$ power, connected to an electric grid, really started in the 1939 with the erection of the world's first megawatt scale turbine, the Smith-Putnam, on Grandpa's Knob in Vermont, USA [1]. Modern turbines for AC power generation have been large structures beginning with the 53 meter rotor of the Smith-Putman turbine. The "fuel crisis" of the 1970s further accelerated development of efficient and large wind turbines with the latest designs possessing rotors 126 meters in diameter (Enercon E-126).

Excessive structural vibrations have always been a design concern due to the long slender rotating blades being excited by aerodynamic and gravitational forces, and resonant frequencies have been observed from instrumentation on field tests of turbines. Because of centripetal and Coriolis forces and the effects of tension stiffening, the modal frequencies change as a function of rotation rate. For turbine designers, it is critically important to know the modal frequencies at the designed fixed rotation rate to avoid resonance.

Formalized modal testing of blades and turbines only began in the late 1970's. In this paper, we will describe some of the landmark tests which were conducted during the inception and development of OMA. The development of OMA was the key to the techniques that would be used for these large and flexible structures. To perform a modal test on these large turbines is 
challenging, because they require large excitation forces that are applied well above ground-level. However, wind turbines are obviously located in windy locations, and the ambient wind provides substantial and continuous excitation. This paper is fairly historical in nature as it traces the development of OMA techniques by reviewing specific challenges in turbine testing that have occurred in the evaluation of new designs and validation of turbine models. These developments will be illustrated by specific tests on particular turbines, but the intent of the paper is not to be exhaustive of all tests or all developments in the turbine testing techniques. Generally, there are two basic concepts in wind turbine design, Horizontal Axis Wind Turbines (HAWTs) and Vertical Axis Wind turbines (VAWTs). HAWTs are also described as propeller machines. Both types of turbines provided testing challenges which further motivated the development of OMA techniques in order to perform modal testing of these structures. Initially, OMA testing techniques were applied to VAWTs; but subsequently HAWTs were also tested using these techniques. We will begin this review by describing a very difficult and time consuming test program to validate the mathematical modeling of a rotating VAWT. This program occurred before OMA was even conceived, but it certainly created the motivation for better techniques for modal testing large flexible structures. This initial test will be followed by a description of the first wind turbine test, which used OMA in 1986, the 120 meter tall Éole turbine in Quebec. Following this initial success with a rudimentary technique, a formalize approach to OMA was mathematically developed and applied to a number of turbine tests, using simulated data and 
actual test data from several parked and rotating turbines. Later, a validation technique was developed which compared synthesized auto-spectra with the wind-excited measured spectra. Lastly, we will describe some of the challenges and applications in the transition from VAWTs to HAWTs.

\section{Initial Modal Testing for Wind Turbines (Before OMA)}

Prior to 1982, the appropriate mathematical modeling procedures for rotating VAWTs were yet to be developed. Previously, helicopter technology was utilized for VAWTs which did not include all the necessary rotating coordinate system effects required for a VAWT. (See, for example, [2 and 3].) A new capability was developed in 1982, [3], which proposed to include all appropriate terms, but required experimental validation so that it could be applied to new and existing turbine designs. This new capability included the standard effects of tension stiffening, as well as the centrifugal and the Coriolis terms. In the system of equations, the centrifugal and Coriolis terms are a function of the rotation speed and significantly affect the modal frequencies and shapes [4].

To experimentally validate this new modeling capability, a small 2 meter VAWT was chosen as the test bed, shown in Figure 1. This test is described in detail in [4]; here we will briefly describe some key issues which motivated the development of OMA techniques. This 2 meter VAWT was built as a research turbine, and not at all representative of a production turbine; but very useful for validating this new modeling capability because it could be operated at a wide variety of rotation rates. The first ten modal frequencies were predicted as a 
function of turbine rotation speed and are plotted in Figure 2, from the parked condition (zero rpm) to $800 \mathrm{rpm}$. One can see how dramatically the modal frequencies vary with the turbine rotation speed. Obviously, one needs to know the modal frequency at the intended fixed operating speed.

The model validation test included measuring the modal frequencies and shapes at the parked condition and at seven different operating speeds up to 800 rpm. The parked test was performed in a traditional manner using impact excitation and accelerometers. For the rotating tests, nine slip rings were part of the instrumentation system that included seven strain gages and two accelerometers. However, the real difficulty was not in measuring the response during rotation, but in structurally exciting the turbine. In order to excite the turbine with a measurable input force while it is rotating, a quick-release device was designed and attached to the tower so it would rotate with the turbine. The device actually created a pre-load between the tower and one of the two blades, and then this load would be suddenly released during rotation of the turbine, creating a step-relaxation input. The input from the step-relaxation device worked fine with the force signal transmitted through the slip rings to the data acquisition system. A schematic of the device is shown in Figure 3 and can be seen in the photo of Figure 1.

The final results from the modal test were quite satisfying as they validated the new modeling approach. The experimental data matched the predictions quite well, particularly for the low frequency modes. The results are shown on Figure 4 with the experimental data overlaid on the predictions from 
the model. One can see that for the lowest seven modes, the correlation between test and predictions is very good with some deterioration in the correlation as one looks at the higher modes. Thus, we see that step-relaxation is a fine excitation technique.

The problem with the step-relaxation technique was that the device had to be reloaded for every input, which meant bringing the turbine down to the parked condition, reloading the device, and then rotating the turbine back up to its rotation speed. This was extremely time-consuming, particularly because we wanted to test the turbine at many rotation speeds. In order to collect all the required signals, the test required over a month of testing. Although steprelaxation worked very well with very good energy input, particularly at low frequencies as discussed in [4], the time required for a rotating test was extreme. This time requirement caused us to think about alternatives to step-relaxation whether one was testing a parked or a rotation turbine. Certainly for a production-scale, turbine that was rotating, step-relaxation would be almost impossible, although one could still utilize step-relaxation for parked turbines.

\section{First OMA on a Wind Turbine, the 120 Meter Tall Éole Turbine}

In 1986, we had the opportunity to think about alternatives to steprelaxation for really large built on-site structures. Sandia Labs had received a request from Shawinigan Engineering Co. of Montreal, Canada to assist them in performing a modal test for their newly erected Éole wind turbine in eastern Quebec, in the parked condition. The Éole, whose photograph is in Figure 5, was 110 meters tall, 67 meters in diameter, and very flexible with several modes 
below $1.0 \mathrm{~Hz}$. Because the turbine was such a massive structure, exciting it adequately with a step-input seemed quite difficult; however, no one had formally utilized and documented an OMA approach to modal testing previously. No doubt, numerous engineers had previously examined strain gage or accelerometer responses in the frequency domain, excited by operational inputs, and identified resonant frequencies. However, we required a full modal analysis including mode shapes, frequencies, and damping values for comparison with a finite element predictions for the turbine. This test and the results have been previously reported in more detail in the $6^{\text {th }}$ IMAC conference in 1988 [5] and the Modal Analysis Journal [6].

Due to our lack of any experience with OMA, our test program included both the step-relaxation input and an initial rudimentary approach to OMA. The step excitation included two distinctly located inputs on one of the blades with $45,000 \mathrm{~N}$ of force and on the tower with $135,000 \mathrm{~N}$ of force. These inputs were used to measure standard acceleration-over-force Frequency Response Functions (FRFs). These FRFs were then utilized with the available modal analysis algorithms to compute the modal parameters. This magnitude of stepexcitation force required significant hardware with a detailed cable design, a diesel-powered winch, and explosive cable cutters as well as a long test duration on the site. With 45 accelerometers and a 16 channel data acquisition system, numerous inputs were required on both the blade and the tower. Fortunately, those two inputs were adequate to excite all the modes of interest. 
For the OMA data, four separate response sets were created so that four reference channels could be repeated with each set of data. In spite of collecting four sets of data with long records, the operational (wind-excited) data collection was much faster than the step-relaxation data collection because of the time required to set-up the step-relaxation device. At the time, we called this wind excited or natural excitation testing, rather than OMA, as that term had yet to be created. As mentioned the OMA algorithm was fairly rudimentary which consisted of measuring auto-spectral and cross-spectral densities of all the channels in a particular data set. The mode shapes were taken to be real, so the amplitudes and signs of the shape components were extracted from the crossspectral densities. The reference channels which were repeated for each data set were used to normalize the mode shape components between the four sets of data. The auto-spectral densities were use to estimate the modal frequencies for the modes although damping was not estimated. Consequently, at the end of the test program, we had two distinct sets of data, one set consisted of responseonly (OMA) data excited by the wind, and the second was classic FRF data excited with step-relaxation inputs. Mode shapes and modal frequencies were estimated using both sets of data.

The modal frequency data extracted from both the conventional FRFs and the response-only data is shown in Table 1 . There a total of 12 modes listed in the table with various shape descriptions which include the terms: tower, blades, out-of-plane, in-plane, and twist. The plane is defined by the two axes of the two blades and the tower. The blades are softer when bending in-plane, that is, 
flatwise (or flapwise) rather than out-of-plane which is edgewise bending. There are symmetric and anti-symmetric blade mode shapes, and at higher frequencies, one obtains the higher versions for each of these shape types. More importantly than the specifics of the mode shapes, the comparison between the frequencies extracted from the conventional FRFs and those extracted from the wind-excited (OMA) data shows an amazing correlation. The very small differences that we observe are most likely due to estimation error when analyzing the data. There is really only one discrepancy between the two sets of frequencies. The third tower out-of-plane mode was not readily observable in the wind-excited data, so that modal frequency could not be estimated using the wind data. Other than that small issue (missing a mode), these test results validate that wind-excitation is a very viable alternative to step-relaxation for wind turbine testing. And reduced testing time for wind-excitation makes it a much faster and less expensive technique for exciting these large structures. This test and the results clearly established this new technology for testing large structures that are exposed to some environmental inputs, in this case, wind inputs. This success led the way to developing a formal process, which was named the Natural Excitation Technique (NExT), in contrast to the standard modal testing technique which uses artificial excitation, such as step-relaxation. In the following sections, we will describe the development of NExT, its validation, and its application to both VAWTs and HAWTs, parked and rotating.

\section{Theoretical Basis for an OMA Process, NExT}

A critical step in the development of NExT was to find a function that could be measured from operational data, but possessed a clear relationship with and a 
dependence on the modal parameters of the structure. For NExT, the function selected was cross-correlation functions between responses without a measurement of the input force. This section outlines the development of the relationship between the cross-correlation function and modal parameters. The full details of this development can be found in [7-9].

The derivation begins by assuming the standard matrix equations of motion:

$[\mathrm{M}]\{\ddot{x}(\mathrm{t})\}+[C]\{\dot{x}(\mathrm{t})\}+[\mathrm{K}]\{\mathrm{x}(\mathrm{t})\}=\{f(t)\}$

where

$[\mathrm{M}]$ is the mass matrix;

$[\mathrm{C}]$ is the damping matrix;

$[\mathrm{K}]$ is the stiffness matrix;

$\{\mathrm{f}\}$ is a vector of random forcing functions;

$\{\mathrm{x}\}$ is the vector of random displacements; and $\mathrm{t}$ is time.

Equation (1) can be expressed in modal coordinates using the standard modal transformation and diagonalized matrices (assuming proportional damping). A solution to the resulting scalar modal equations can be performed via the convolution or a Duhamel integral [10] and assuming a general forcing function \{\} with zero initial conditions. The solution can be converted back into physical coordinates and specialized for a single input force and a single output using appropriate mode shape matrix entries. The following equation results:

$$
\mathrm{x}_{\mathrm{ik}}(\mathrm{t})=\sum_{\mathrm{r}=1}^{\mathrm{n}} \psi_{\text {ir }} \psi_{\text {kr }} \cdot \int_{-\infty}^{\mathrm{t}} \mathrm{f}_{\mathrm{k}}(\tau) \mathrm{g}^{\mathrm{r}}(\mathrm{t}-\tau) \mathrm{d} \tau
$$


where

$$
g^{r}(t)=0, \text { for } t<0 ; g r(t)=\frac{1}{m^{r} \omega_{d}^{r}} \exp \left(-\zeta r \omega_{n}^{r} t\right) \sin \left(\omega_{d}^{r} t\right), \text { for } t \geq 0 ;
$$

$\omega_{\mathrm{d}}^{\mathrm{r}}=\omega_{\mathrm{n}}^{\mathrm{r}}\left(1-\zeta^{2}\right)^{1 / 2}$ is the damped modal frequency;

$\omega_{\mathrm{n}}^{\mathrm{r}}$ is the $r^{\text {th }}$ modal frequency;

$\zeta^{\mathrm{r}}$ is the $r^{\text {th }}$ modal damping ratio;

$\mathrm{m}^{\mathrm{r}}$ is the $r^{\text {th }}$ modal mass;

$\mathrm{n}$ is the number of modes;

$\psi_{\text {ir }}$ is the $i^{\text {th }}$ component of mode shape $r$; and

$\mathrm{t}$ is the time.

The next step of the theoretical development is to form the cross-correlation function of two responses $\left(\mathrm{x}_{\mathrm{ik}}\right.$ and $\mathrm{x}_{\mathrm{jk}}$ ) due to a white-noise input at a particular input point k. Reference [11] defines the cross-correlation function $\Re$ as the expected value of the product of two responses evaluated at a time separation of $\mathrm{T}$,

$$
\Re_{i j k}(T)=E\left[x_{i k}(t+T) x_{j k}(t)\right]
$$

where $E$ is the expectation operator.

Substituting Equation (2) into (3) and recognizing that the force $f$ is the only random variable, then the expectation operator functions only on the forcing function. Using the definition of the autocorrelation function [11], and assuming for simplicity that the forcing function is white noise (this is only approximately true), then the expectation operation collapses to a scalar times a Dirac delta function. The Dirac delta function collapses one of the Duhamel integrations embedded in the cross-correlation function. The resulting equation can be simplified via a change of variable of integration $(\lambda=t-\tau)$. Using the definition of $g$ from Equation (2) and the trigonometric identity for the sine of a sum results in all the terms involving $T$ being separated from those involving $\lambda$. This separation allows terms that depend on $T$ to 
be factored out of the remaining integral and out of one of the modal summations. This results in

$$
\Re_{i j k}(T)=\sum_{r=1}^{n}\left[A_{i j k}^{r} \exp \left(-\zeta \omega_{\mathrm{n}}^{\mathrm{r}} T\right) \cos \left(\omega_{\mathrm{d}}^{\mathrm{r}} T\right)+B_{i j k}^{r} \exp \left(-\zeta^{\mathrm{r}} \omega_{\mathrm{n}}^{\mathrm{r}} T\right) \sin \left(\omega_{\mathrm{d}}^{\mathrm{r}} T\right)\right]
$$

where $\mathrm{A}_{\mathrm{ijk}}^{\mathrm{r}}$ and $\mathrm{B}_{\mathrm{ijk}}^{\mathrm{r}}$ are independent of $\mathrm{T}$, are functions of only the modal parameters, contain completely the remaining modal summation, and are shown below.

$$
\left\{\begin{array}{c}
A_{\mathrm{ijk}}^{\mathrm{r}} \\
B_{\mathrm{ijk}}^{\mathrm{r}}
\end{array}\right\}=\sum_{\mathrm{s}=1}^{\mathrm{n}} \frac{\alpha_{\mathrm{k}} \psi_{\mathrm{ir}} \psi_{\mathrm{kr}} \psi_{\mathrm{js}} \psi_{\mathrm{ks}}}{\mathrm{m}^{\mathrm{r}} \omega_{\mathrm{d}}^{\mathrm{r}} \mathrm{m}^{\mathrm{s}} \omega_{\mathrm{d}}^{\mathrm{s}}} \cdot \int_{0}^{\infty} \exp \left(-\zeta^{\mathrm{r}} \omega_{\mathrm{n}}^{\mathrm{r}}-\zeta^{\mathrm{s}} \omega_{\mathrm{n}}^{\mathrm{s}}\right) \lambda \cdot \sin \left(\omega_{\mathrm{d}}^{\mathrm{s}} \lambda\right)\left\{\begin{array}{c}
\sin \left(\omega_{\mathrm{d}}^{\mathrm{r}} \lambda\right) \\
\cos \left(\omega_{\mathrm{d}}^{\mathrm{r}} \lambda\right)
\end{array}\right\} \mathrm{d} \lambda
$$

Equation (4) is now the key result of this derivation because many timedomain modal analysis algorithms utilized impulse response functions as the input data for estimating the modal parameters. We see that Equation (4) shows that the cross-correlation function has the same characteristics as the impulse response function, a sum of decaying sinusoids with the same damping and frequency as the impulse response function. Thus, cross-correlation functions can be used in place of impulse response functions in these time-domain modal parameter estimation algorithms. Consequently, Equation (4) provides us with the desired function that can be measured from operational data and used to extract the modal parameters. The reader can refer to [7-9] for more details of the intermediate steps in this derivation. These references also provide verification of this derivation, using the maximum of an autocorrelation function and a cross-correlation identity.

\section{Verification of NExT (OMA) Using Simulated Data}

The next step in the development of NExT was to use computationally simulated data with the known modal parameters and compare the results derived 
using NExT with the known modal parameters. For this activity, a simulation code VAWT-SDS had been developed to compute the time domain response of VAWTs during rotation in turbulent wind [12]. The structural model utilized in VAWT-SDS simulation was also used to calculate the modal frequencies and modal damping in the simulation. VAWT-SDS generated analytical time-domain data, which were then input to the NExT procedure, and the resulting modal data were compared to the known frequencies and damping information to test the capabilities of NExT.

The specific turbine modeled was the DOE/Sandia 34-m VAWT Testbed, which was located in Bushland, Texas. Figure 6 shows a schematic of this turbine with the location of the strain gages. Simulated data were generated for the 34-m Testbed using a $30 \mathrm{rpm}$ rotation rate and $9.0 \mathrm{~m} / \mathrm{s}$ turbulent winds with a $15 \%$ turbulence intensity. Stiffness proportional damping sufficient to produce a damping ratio of $0.2 \%$ at $1.4 \mathrm{~Hz}$ was included in the model. Time histories of 2048 points for eight strain gauge outputs were generated using a step size interval of $0.04 \mathrm{~s}$. Ten sets of independent random time histories were calculated with similar random wind conditions to allow ensemble averaging. Sensor noise was simulated by adding a white-noise signal to each simulated time history. The standard deviation of this additive noise signal was $2 \%$ of the standard deviation of each time history.

VAWT-SDS used the Newmark-Beta numerical integration scheme, and the approximations inherent in this procedure produced period elongations [13]. The frequency shifts created by numerical integration were calculated and a correction was added to the analytical values [14]. NExT was then used to estimate modal frequencies and damping ratios from the simulated data so that the NExT results 
and the analytical values could be compared. SDRC's PolyReference algorithm was used to perform the time-domain analysis on the auto- and cross-correlation functions represented by Equation (4).

Table 2 shows the results of the comparison. The agreement between the actual and the NEXT generated modal frequencies is excellent. The only exceptions to this are the first two modes at $1.27 \mathrm{~Hz}$ and $1.35 \mathrm{~Hz}$. These modes are very closely spaced, making it difficult to obtain accurate results from modal analysis of the correlation data. Generally, the agreement between the VAWT-SDS specified damping ratios and the calculated damping ratios is good, with a few exceptions. The damping ratios for the first flatwise anti-symmetric $(1.27 \mathrm{~Hz})$ and the first flatwise symmetric $(1.35 \mathrm{~Hz})$ modes were not estimated well because these modes could not be easily separated. The higher modes $(3.65 \mathrm{~Hz}, 3.73 \mathrm{~Hz}$, and $3.88 \mathrm{~Hz})$ have NExT estimated damping ratios that are lower than the specified damping ratios. The amplitudes of these modes are low compared to the noise level, which adversely affected the estimates. Obtaining longer time histories would improve the accuracy by reducing the effects of the included noise. However, considering the accuracy of estimating damping with modal analysis software, these differences in the damping are quite acceptable. The ability of NExT to reproduce known the modal frequencies and specified damping values further increased our confidence in the application of OMA to actual field tests of turbines.

\section{Verification of NExT (OMA) Using Conventional Modal Test Results}

Another activity which was performed to verify NExT was to compare to conventional modal test data. For this activity, a FloWind Corporation 19-m VAWT 
in Altmont Pass, Califomia was tested using conventional modal testing techniques [15] during quiescent daytime winds. NExT was then used during periods of more substantial winds, above $7 \mathrm{~m} / \mathrm{s}$. The turbine was parked (non-rotating) during all testing. Accelerometers were used to measure the response at specific locations on the turbine. This allowed a comparison between modal parameters estimated by NExT and those estimated using conventional testing techniques (step-relaxation testing).

Table 3 compares the modal frequencies and modal damping ratios of the 19-m VAWT as determined from the conventional testing and from NExT. The two methods produced estimates of the modal frequencies that are in good agreement, particularly in view of the temperature difference between day and night. The average difference for the ten modal frequencies is only $0.5 \%$. Further, the modal damping ratios of all six of the tower modes (rotor twist, tower in-plane, tower out-of-plane) are very similar. However, the modal damping ratios of all four blade flatwise modes (flatwise symmetric and flatwise anti-symmetric) are substantially higher from NEXT estimates. This difference was shown to be due to a drag phenomenon similar to that experienced by an oscillating flat-plate normal to a strong wind $[16,17]$. Reference $[7]$ contains the results of a simplified calculation, which predicts $1.2 \%$ added damping due to the aero-drag effects for the first blade flatwise modes. This would account for the $1.1 \%$ and $1.3 \%$ additional damping for the first blade flatwise modes as seen in Table 3 . The utility of performing modal testing in an operating environment is further revealed by this operating condition creating additional effective damping. Since the traditional modal testing was 
performed in quiescent winds, it failed to observe the additional damping mechanism that was observed by the natural excitation testing. PolyReference was again used to perform the time-domain analysis. Overall, the comparison of results from NExT with those obtained using conventional methods further verifies the accuracy of NEXT in particular and OMA in general.

The presence of the air drag phenomenon shows that NExT extracts the total damping, structural and aero-elastic. This is the desired situation for operational testing because aero-elastic damping adds to structural damping during rotation. However for a parked turbine testing, which is designed to capture only the structural damping, conventional modal testing techniques may be more appropriate. The need for quiescent winds during such testing is even more apparent from these results.

\section{Verification of NExT (OMA) via Auto-spectrum Synthesis}

When performing any type of modal test, one wants to verify the adequacy of the parameter extraction process by synthesizing the original test data and then comparing the synthesis with the test data. For traditional modal testing, one synthesizes the originally measured Frequency Response Functions (FRFs). For

NExT the auto-spectra are synthesized to verify the adequacy of the estimated modal parameters. For VAWTs which undergo significant aero-elastic and rotational loads during operation, a complete verification of NEXT requires a modal test on the rotating structure. Specific interest is placed on determining the modal damping that arises from these aero-elastic interactions. NExT was used to extract the modal frequencies and the damping values using data from the DOE/Sandia 
34-m Testbed turbine during rotation at $28 \mathrm{rpm}$. The wind speed during the data collection was approximately $10 \mathrm{~m} / \mathrm{s}$. Twelve strain gauges were used as the sensors. Time histories of 30 minutes were recorded at 20 samples per second. These time histories were used to calculate averaged correlation functions of 1024 points. The Eigensystem Realization Algorithm (ERA) was used to perform the time-domain analysis. Subsequently, the modal frequencies and damping values were used to synthesize the auto-spectra of the measured responses. The magnitudes of the modal contributions to the spectrum were selected via a least squares fit of the measured data. Hence the magnitude (or mode shape information) is selected in the synthesis process and not verified as part of this exercise. Note that the auto-spectra were also directly measured during the test to allow the desired comparison for validation.

Figure 7 shows actual test data overlaid with a synthesis of the auto-spectrum of the blade edgewise strain at the bottom of one of the blades while operating in the conditions listed above. This figure illustrates the usefulness and the limits of this graphical comparison as well as several aspects of the modal parameter estimation process. The labels $1 \mathrm{P}, 2 \mathrm{P}, 3 \mathrm{P}, 4 \mathrm{P}$, and $5 \mathrm{P}$ denote the per-rev harmonics of the rotation rate. These harmonics are captured very well, although NExT operated on the harmonics as though they were actual modes with very low damping. Of course, if one knows the rotation speed, then it is easy to discriminate the responses due to the harmonics. In contrast to the measured data, the synthesis has very deep zeros but does not contain the noise which would fill up the valleys, as observed for the measured data. 
The first tower in-plane mode, $1 \mathrm{Ti}$, and the second propeller mode (rotor twist), $2 \mathrm{Pr}$, reveal a good synthesis. The near exact synthesis of the frequency and the shape of the peak produces confidence in the modal frequency and damping ratio computed using NExT. The first blade edgewise mode, $1 \mathrm{Be}$, and the second blade flatwise modes, $2 \mathrm{~F}$, have the correct modal frequency estimates, but the auto-spectrum coefficient was not estimated closely. This could be due to an incomplete mathematical representation of the auto-spectrum, noise in the experimental auto-spectrum, or numerical interactions with adjacent modes. The auto-spectrum synthesis provides little information for these modes about the quality of the modal damping estimates in such cases.

The first two blade flatwise modes, denoted as $1 \mathrm{~F}$, are coincident with the $3 \mathrm{P}$ harmonic. The auto-spectrum synthesis provides no information about the quality of the modal damping ratio estimate for this situation. A technique to remove the $3 \mathrm{P}$ harmonic would probably improve the results. Alternatively, an auto-spectrum synthesis at another rotational speed would separate the $1 \mathrm{~F}$ resonance from the $3 \mathrm{P}$ response. The third blade flatwise modes $(3 \mathrm{~F})$, the third propeller mode $(3 \mathrm{Pr})$, and the second tower in-plane mode (2Ti) are closely grouped. Therefore, modal parameters for these modes should be verified using data from different sensors. Finally, the second blade edgewise $(2 \mathrm{Be})$ is in a region of low signal-to-noise ratio. Information on the quality of this extracted mode could also be obtained from different data channels.

The comparison of the measured auto-spectra and the synthesize spectra is a good test of the adequacy of the extracted modal parameters. However, it appears 
to be a more difficult comparison than the traditional modal testing which uses the FRFs. Auto-spectra have much more additive noise than measured FRFs.

\section{OMA Results Using NExT For a Rotating VAWT}

This section discusses an application of NExT to a rotating VAWT. NEXT was used to extract modal damping using data from the DOE/Sandia 34-m Testbed during rotation at $0,10,15,20,28,34$, and $38 \mathrm{rpm}$. The wind speed during these tests was also approximately $10 \mathrm{~m} / \mathrm{s}$. The twelve strain gauges were used as the sensors in all of these analyses. Time history length, sample rate, correlation block size, and the time domain analysis processor are all the same as provided in the previous section. Figure 8 is a plot of the modal frequencies of the 34-m Testbed measured using NExT, and clearly reveals the modal frequencies changing as a function of rotation rate. For turbine designers, it is critically important to know the modal frequencies at the designed fixed rotation rate to avoid resonance.

Figure 9 shows a plot of modal damping ratio, as calculated using NExT, versus turbine rotation rate for the blade flatwise modes. The damping was the key result of this testing project, because the measured operational damping was required for the analysis as there was no prediction of damping. From the figure, one can see that the damping ratios of these modes generally increase with turbine rotation rate. The increase in damping is quite significant; for example, the first flatwise damping increases from $2 \%$ to $7 \%$. The notable exception is the second blade flatwise mode between $15 \mathrm{rpm}$ and $28 \mathrm{rpm}$. Such a decrease in the damping value could be due to changes in the mode shape to a more lightly damped shape. Because the aero-coupling varies with the shape and rotation speed, the resulting 
mode shape could be less affected by the aerodynamic damping terms and, therefore, the damping ratio would drop.

\section{OMA Results Using NExT For a Rotating HAWT}

This section provides an additional application using NExT on a different rotating system - the Horizontal Axis Wind Turbine (HAWT). Figure 10 shows a field of modern wind turbines offshore in Denmark. A controlled yaw or upwind machine, as compared to a downwind machine, provides the most direct application of NEXT because the kinematics of the machine is primarily limited to rotation of the blades, rather including the yaw of the entire rotor. Consequently the harmonics of the rotation rate are observed in the data as well as the elastic vibrations of the system (as seen in the previous VAWT example). The machine used for this example was a Northern Power Systems 100-kW machine [18]. This machine is a two-bladed upwind HAWT with a teetering rotor. The rotor diameter is 17.8 meters and contains fiberglass blades. Three strain gauge locations were available for the test. These included a strain gauge set which measured flapwise bending (out of the rotor plane) and a gauge set which measured edgewise bending (in the rotor plane) at the base of one blade. The final gauge set measured flapwise bending of the second blade $30 \%$ up from the root. The data used in this study involved wind speeds of $4.5,7.0,9.0,11.0$, and $13.0 \mathrm{~m} / \mathrm{s}$ while the turbine was rotating at $72 \mathrm{rpm}$. The data were sampled at 36 samples a second. Table 4 contains the frequencies and damping factors for all the modes found below $10 \mathrm{~Hz}$ while operating in $9 \mathrm{~m} / \mathrm{s}$ winds. There is a clear difference in damping ratio between the harmonics (apparent numerical 
damping) which were less than $1 \%$ and the true modes (actual damping) which were all greater than $1 \%$. This was one of the clear indicators of a harmonic response due to the rotation, besides the frequency being a multiple of the rotation speed.

Figure 11 compares of the auto-spectra of the measured data with the synthesis using the NExT extracted parameters, for the root flapwise strain [18]. A high noise floor is apparent; however the peaks are nicely captured, including all the harmonics below $10 \mathrm{~Hz}$, designated as $\mathrm{nP}$, where $\mathrm{n}$ is the harmonic number and $\mathrm{P}$ is shorthand for "per rev". The first edgewise (1E) is not observed well in the flapwise strain, but the second edgewise mode $(2 \mathrm{E})$ is quite well revealed. The third edgewise $(3 \mathrm{E})$ and the second flapwise modes also appear among the harmonic responses.

This application of NExT (OMA) to the HAWT wind turbine is seen to provide very similar results to the previous VAWT example. However, HAWT's can also be configured in a free-yaw or downwind configuration. These machines are very simple to build but have much more complex dynamics. In particular, the uncontrolled yaw degree-of-freedom will couple to the other in-plane dynamics and create entire families of frequency-dependent phenomena, for which the application of OMA is much more complicated [19].

\section{Conclusions}

Performing a modal test on very large structures is a challenging task whether they are wind turbines, buildings, bridges, dams, or aerospace structures. The difficulty is not in measuring the response, but exciting the structure. However, 
all of these structures do experience inputs from the environment. In particular, wind turbines are well excited by the prevailing winds at the site.

Because rotating wind turbines have large dynamic loads due to the aerodynamic lift and drag as well as gravitational inputs, it is particularly important to know their modal parameters to avoid resonance and fatigue. This requirement to perform modal tests on wind turbines initiated the development of a new capability of an output-only modal test using the wind as input. This concept was first utilized on the 110 meter tall Éole turbine in 1988 . These very early ideas were refined and formalized into the procedure which was called the Natural Excitation Technique (NExT). The NExT procedure was a predecessor to the commonly used techniques which are now generally called Operational Modal Analysis (OMA). In contrast to conventional time-domain modal analysis which uses impulse response functions as the input to the estimation algorithms, NExT used auto and cross-correlation functions as the input. It was shown that the correlation function do have the same basic form as impulse response functions, so they can be use directly in the existing software for estimating modal parameters.

NExT was verified with analytically simulated data and with comparison to traditional artificial excitation tests (step-relaxation inputs to produce FRFs). An auto-spectra synthesis capability was created to ascertain the quality of estimated modal parameters similar to synthesis of FRFs for traditional modal testing. Finally NExT (or OMA) was used on a number of turbines including VAWTs and HAWTs, both parked and rotating. NExT was particularly useful for 
measuring the total system damping, both the structural and the aero-elastic, for an operating turbine which could not be predicted from the analysis.

\section{Acknowledgements}

The authors acknowledge the contributions from many colleagues who assisted and inspired much of this work. In particular, we acknowledge James Lauffer who participated in many of the early tests and initiated the development of our approach to OMA. Anthony Gomez was essential in preparation, execution, and performance of many of tests described here. The Wind Energy Technology Department at Sandia National Laboratories provided most the funding for these developments. Sandia is a multiprogram laboratory operated by Sandia Corporation, a Lockheed Martin Company for the United States Department of Energy's National Nuclear Security Administration under contract DE-AC0494AL85000.

\section{References}

[1] D.A. Spera, Wind Turbine Technology, Fundamental Concepts of Wind Turbine Engineering, ASME Press, New York, USA, 1994.

[2] D.H. Hodges and M.J. Rutkowski, Free-Vibration Analysis of Rotating Beams by a Variable-Order Finite-Element Method, AIAA Journal, 10 (1981) 1459-1466.

[3] T.G. Carne, D.W. Lobitz, A.R. Nord, R.A. Watson, Finite Element Analysis and Modal Testing of a Rotating Wind Turbine, AIAA Paper 82-0697, in: AIAA $23^{\text {rd }}$ Structures, Structural Dynamics and Materials Conference, New Orleans, Louisiana, USA, 1982, pp. 335-347. 
[4] T.G. Carne, A.R. Nord, Modal Testing of a Rotating Wind Turbine, in:

Proceedings of the American Solar Energy Society Sixth Biennial Wind Energy Conference and Workshop, Minneapolis, Minnesota, USA, 1983, pp.825-834.

[5] T.G. Carne, J.P. Lauffer, A.J. Gomez, Modal Testing of a Very Flexible $110 \mathrm{~m}$ Wind Turbine Structure, in: Proceedings of the $6^{\text {th }}$ International Modal Analysis Conference, Kissimmee, Florida, USA, 1988, pp. 848-855.

[6] T.G. Carne, J.P. Lauffer, A.J. Gomez, H. Benjannet, Modal Testing an Immense Flexible Structure Using Natural and Artificial Excitation, The International Journal of Analytical and Experimental Modal Analysis, vol 3, no 4, (1988) pp.117-122.

[7] G. H. James, T.G. Carne, J.P. Lauffer, The Natural Excitation Technique (NExT) for Modal Parameter Extraction From Operating Wind Turbines, SAND921666, Sandia National Laboratories, Albuquerque, NM, USA,1993.

[8] G.H. James, T.G. Carne, J.P. Lauffer, A.R. Nord, Modal Testing Using Natural Excitation, in: Proceedings of the $10^{\text {th }}$ International Modal Analysis Conference, San Diego, California, USA, 1992, pp.1209-1216.

[9] G.H. James, T.G. Carne, J.P. Lauffer, The Natural Excitation Technique (NExT) for Modal Parameter Extraction from Operating Structures, International Journal of Analytical and Experimental Modal Analysis, vol. 10, no. 4, (1995) pp. 260-277.

[10] S.H. Crandall, Random Vibration, John Wiley \& Sons, Inc., New York, USA, 1958. 
[11] A. Papoulis, Probability, Random Variables, and Stochastic Processes, McGraw-Hill, New York, NY, 1965.

[12] C.R. Dohmann, P.S. Veers, Time Domain Response Calculations for Vertical Axis Wind Turbines, in: Proceedings of the 8th ASME Wind Energy Symposium, Houston, TX, USA, January, 1989.

[13] K.J. Bathe, E.L. Wilson, Numerical Methods in Finite Element Analysis, Prentice-Hall, Inc., Englewood Cliffs, NJ, 1976.

[14] G.H. James, T.G. Carne, P.S. Veers, Damping Measurements Using Operational Data, ASME Journal of Solar Energy Engineering, vol. 18, no. 3, 1996.

[15] J.P. Lauffer, T. G. Carne, "Modal Testing in the Design Evaluation of Wind Turbines, in: Proceedings of Windpower '85, San Francisco, California, USA, (1985).

[16] E. W. Woolam, Drag Coefficients for Flat Square Plates Oscillating Normal to Their Planes in Air, NASA CR-66544, March 1968, AIAA Paper 78-1692, September 1978.

[17] W.E. Baker, E. Woolam, D. Young, Air and Internal Damping of Thin Cantilever Beams, International Journal of Mechanical Sciences, vol. 9, (1967), pp. 743-766.

[18] G.H. James, Extraction of Modal Parameters from an Operating HAWT using the Natural Excitation Technique (NExT), Wind Energy 1994, SED-Vol.15, edited by W. Musial, S. Hock, and D. Berg, ASME, New York, 1994, also in: 13th ASME Wind Energy Symposium, New Orleans, LA, USA, ( 1994). 
[19] D.J. Malcolm, G.H. James, Stability of a 26m Teetered, Free-Yaw Wind Machine, Wind Energy 1996, SED-Vol.15, edited by W. Musial, S. Hock, and D.

Berg, ASME, New York, 1996, also in: 15th ASME Wind Energy Symposium, Houston, TX, (1996).

\section{Figure Captions}

Fig. 1. The Sandia 2-meter VAWT with Instrumentation

Fig. 2. Predicted Modal Frequencies as a Function of Turbine Rotation Rate

Fig. 3. The Step-Relaxation Device that Rotates with the Turbine Rotor

Fig. 4. A Comparison of Predicted and Measured Modal Frequencies as a Function of Turbine Rotation Rate

Fig. 5. The 110 meter tall Éole Wind Turbine, photographed in 1986.

Fig 6. Schematic of DOE/Sandia 34-m Testbed with indicated strain gauge locations.

Fig 7. Measured and synthesized auto-spectra of blade edgewise strain at $28 \mathrm{rpm}$

Fig 8. Measured modal frequencies as a function of rotation rate for the 34-m Testbed turbine.

Fig 9. Damping of the flatwise modes as a function of rotation rate for DOE/Sandia 34-m Testbed

Fig 10. A field of modern Horizontal Axis Wind Turbines offshore in Denmark

Fig 11. A comparison of the auto-spectra from measured data and the synthesis using the NExT extracted modal parameters 


\section{Table Captions}

Table 1

Comparison of modal frequencies using step-relaxation and wind-excitation

\section{Table 2}

Comparison of modal parameters extracted using NExT with the analytical values

\section{Table 3}

Comparison of modal frequencies and damping values computed with NEXT and traditional techniques

\section{Table 4}

Frequencies (modes and rotation harmonics) and damping values for a HAWT in $9 \mathrm{~m} / \mathrm{s}$ winds 


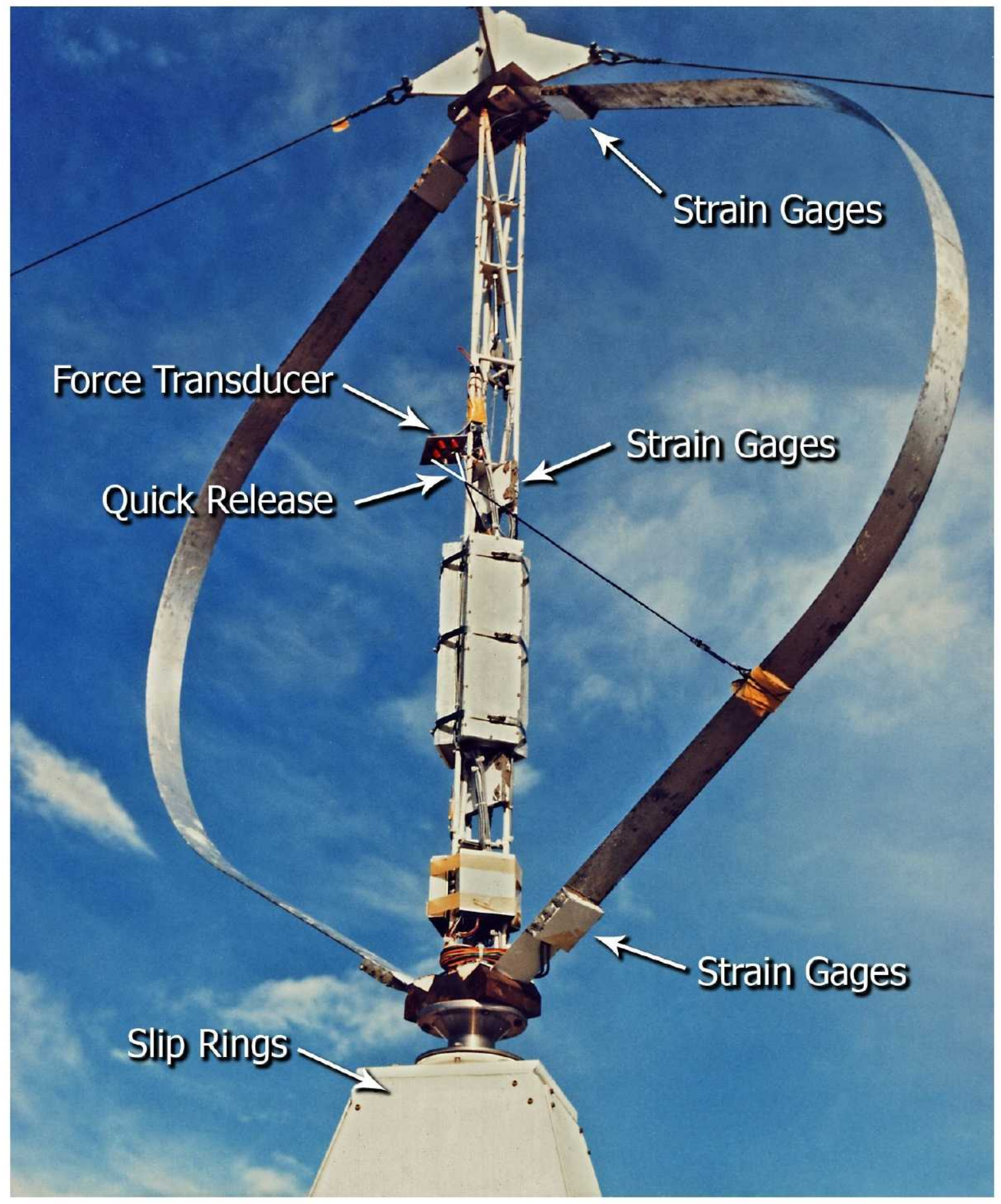

Fig. 1. The Sandia 2-meter VAWT with Instrumentation 


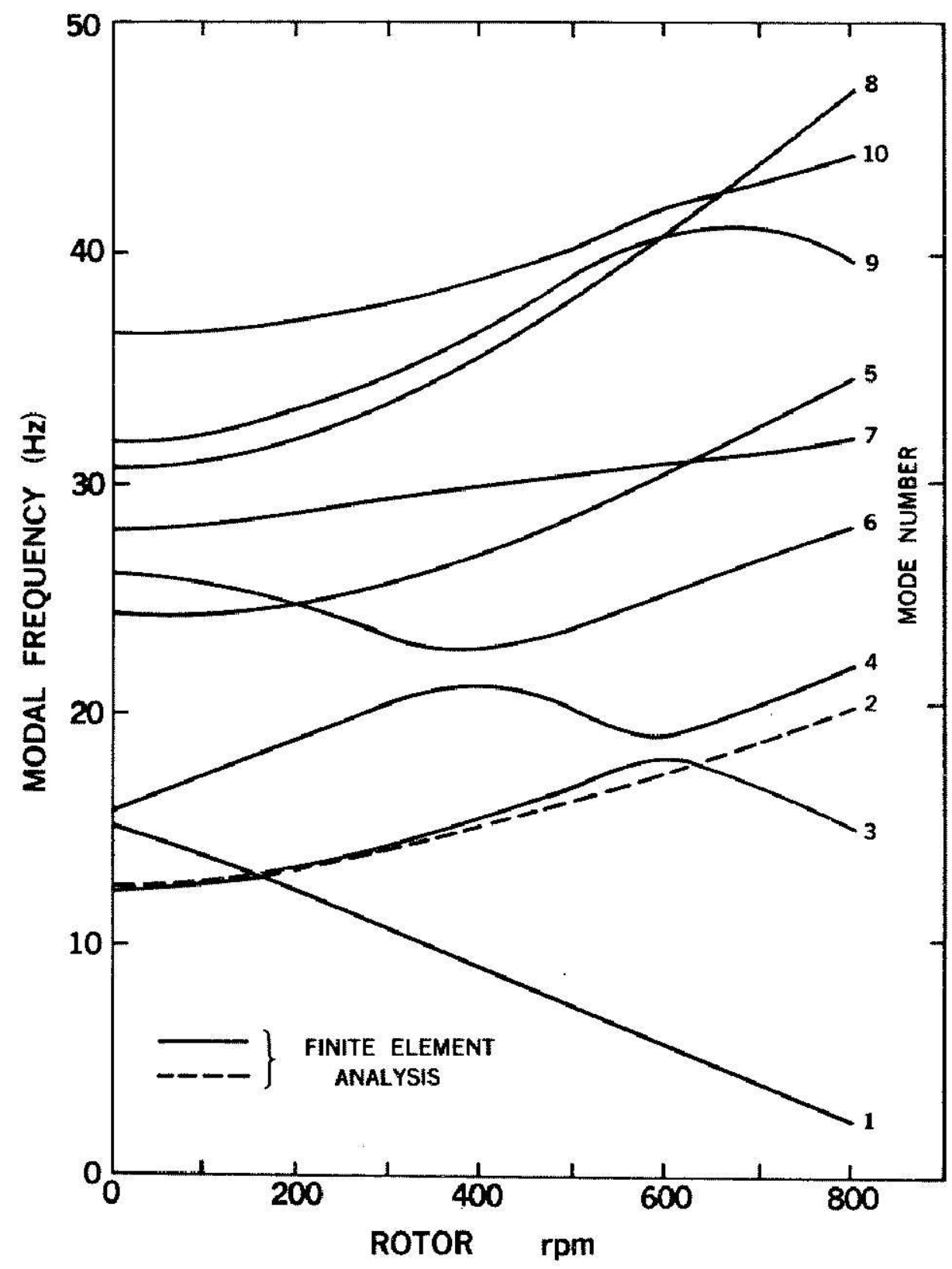

Fig. 2. Predicted Modal Frequencies as a Function of Turbine Rotation Rate 


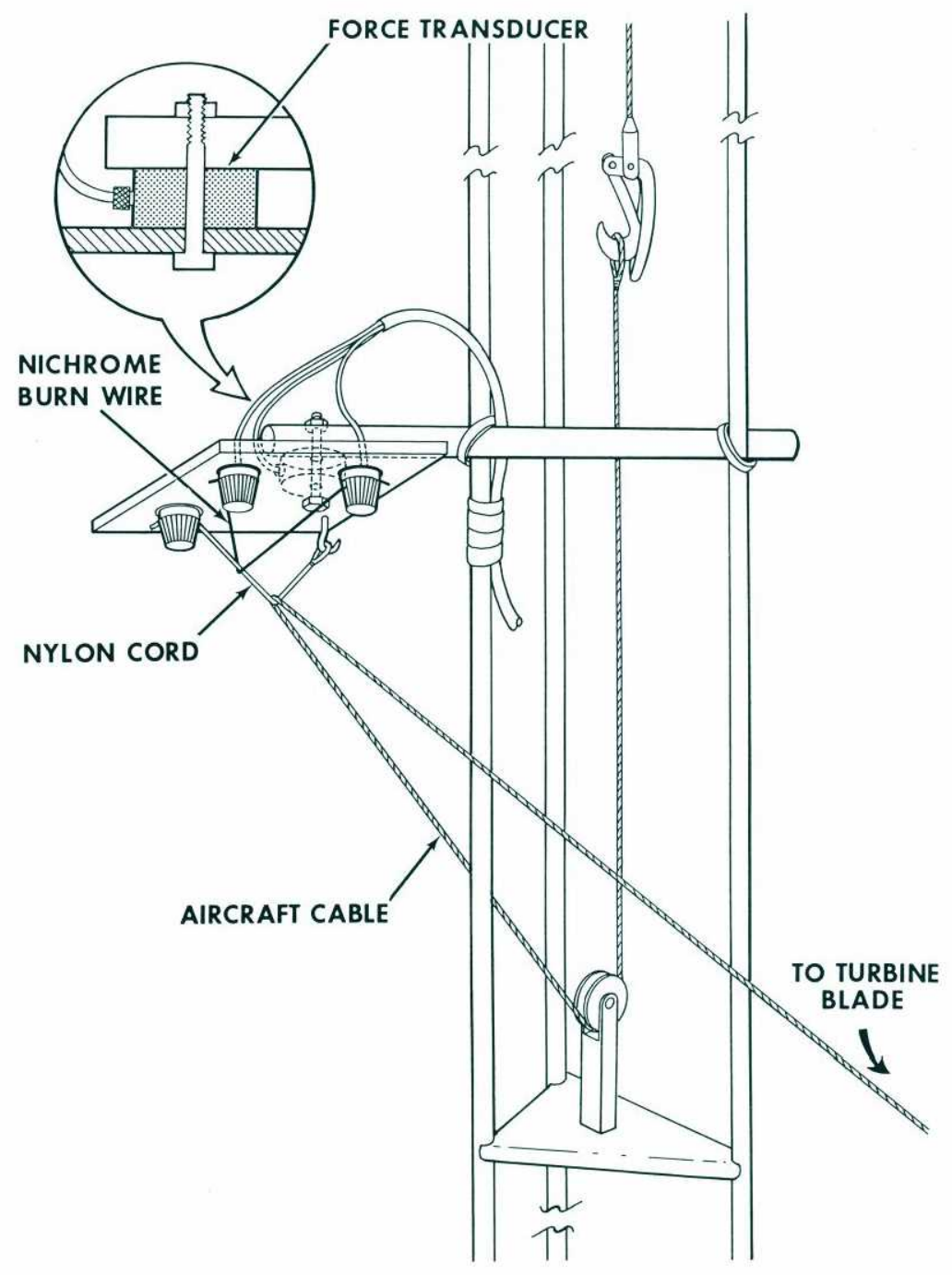

Fig. 3. The Step-Relaxation Device that Rotates with the Turbine Rotor 


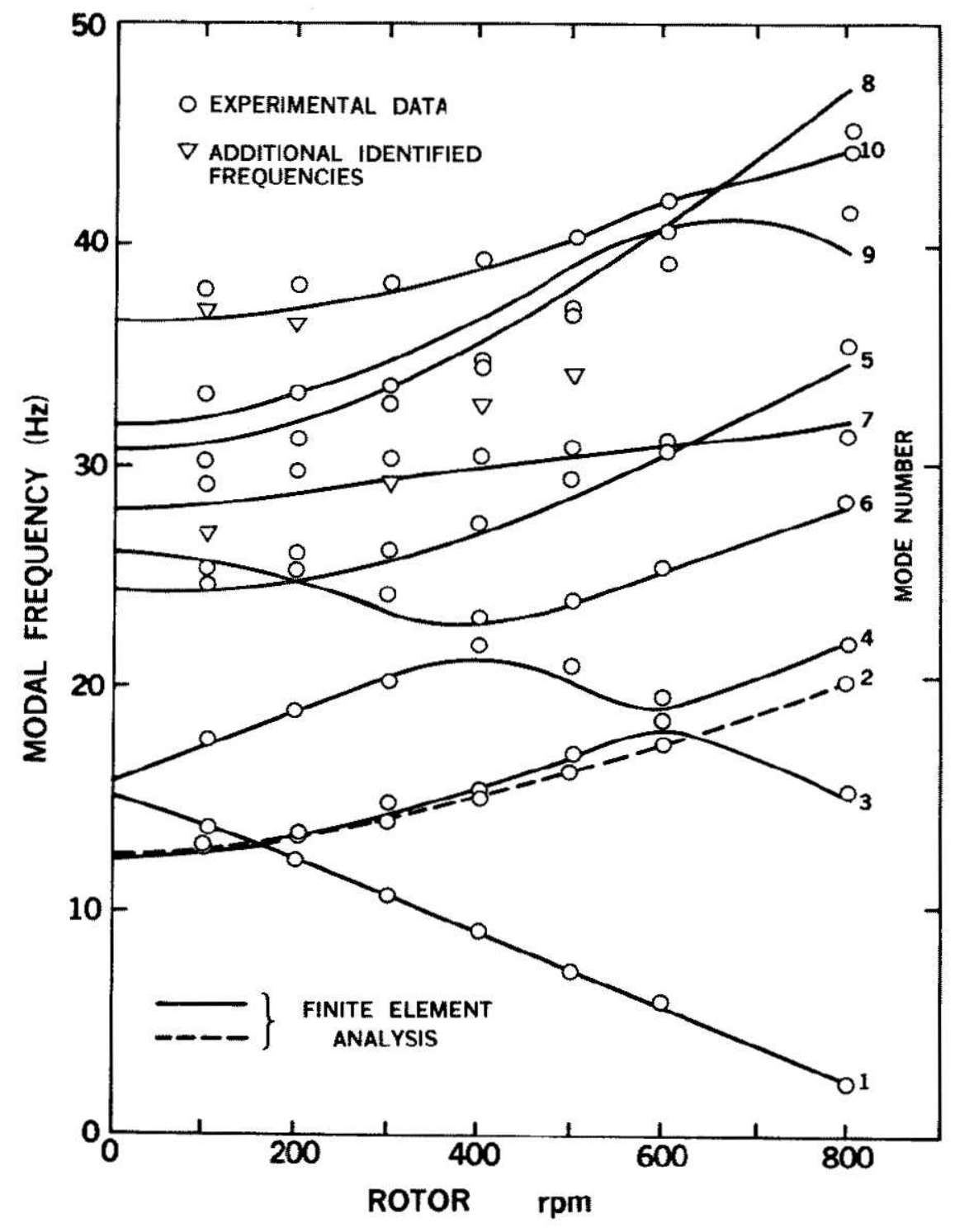

Fig. 4. A Comparison of Predicted and Measured Modal Frequencies as a Function of Turbine Rotation Rate 


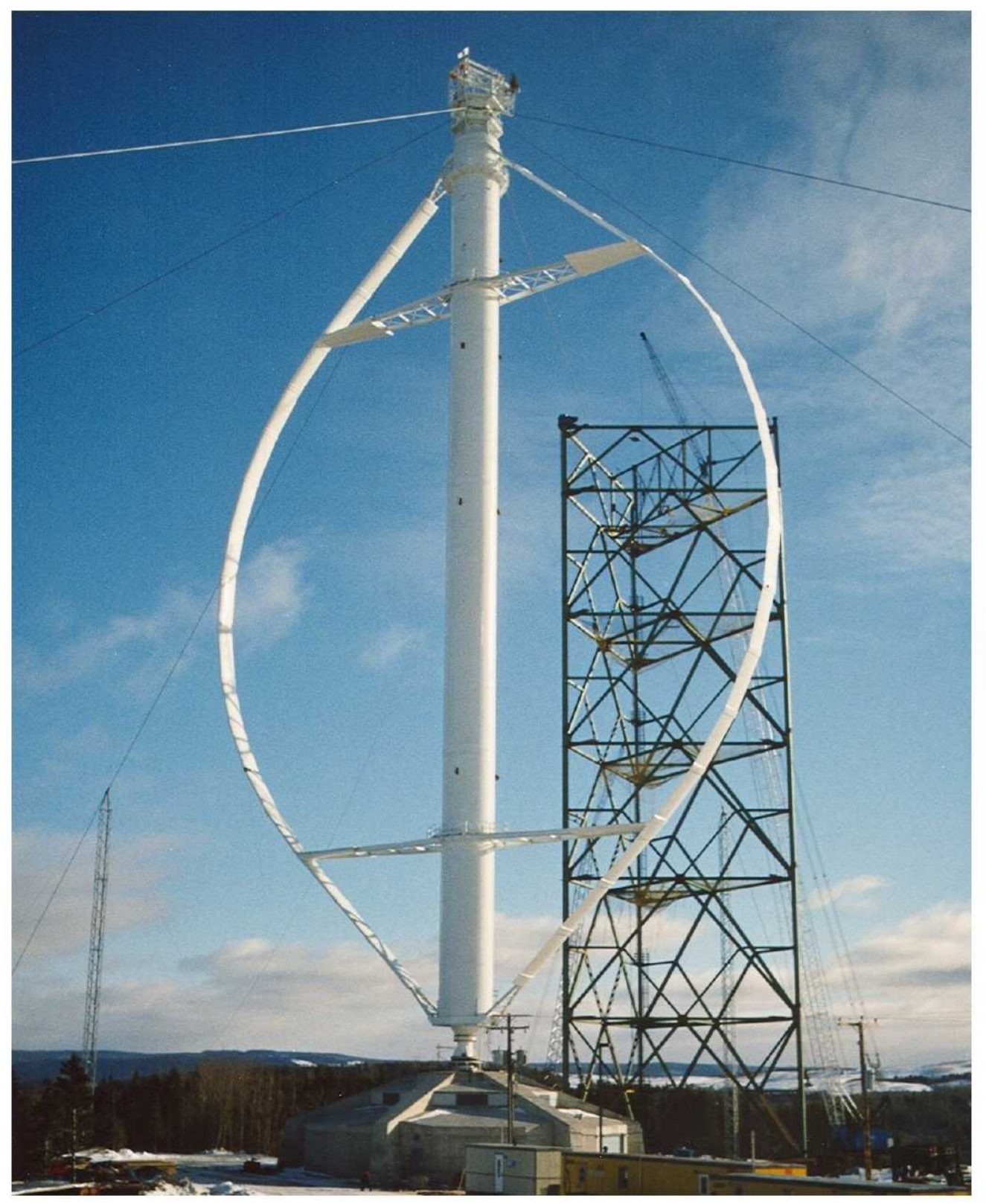

Fig 5. The 110 meter tall ÉOLE Wind Turbine, photographed in 1986 


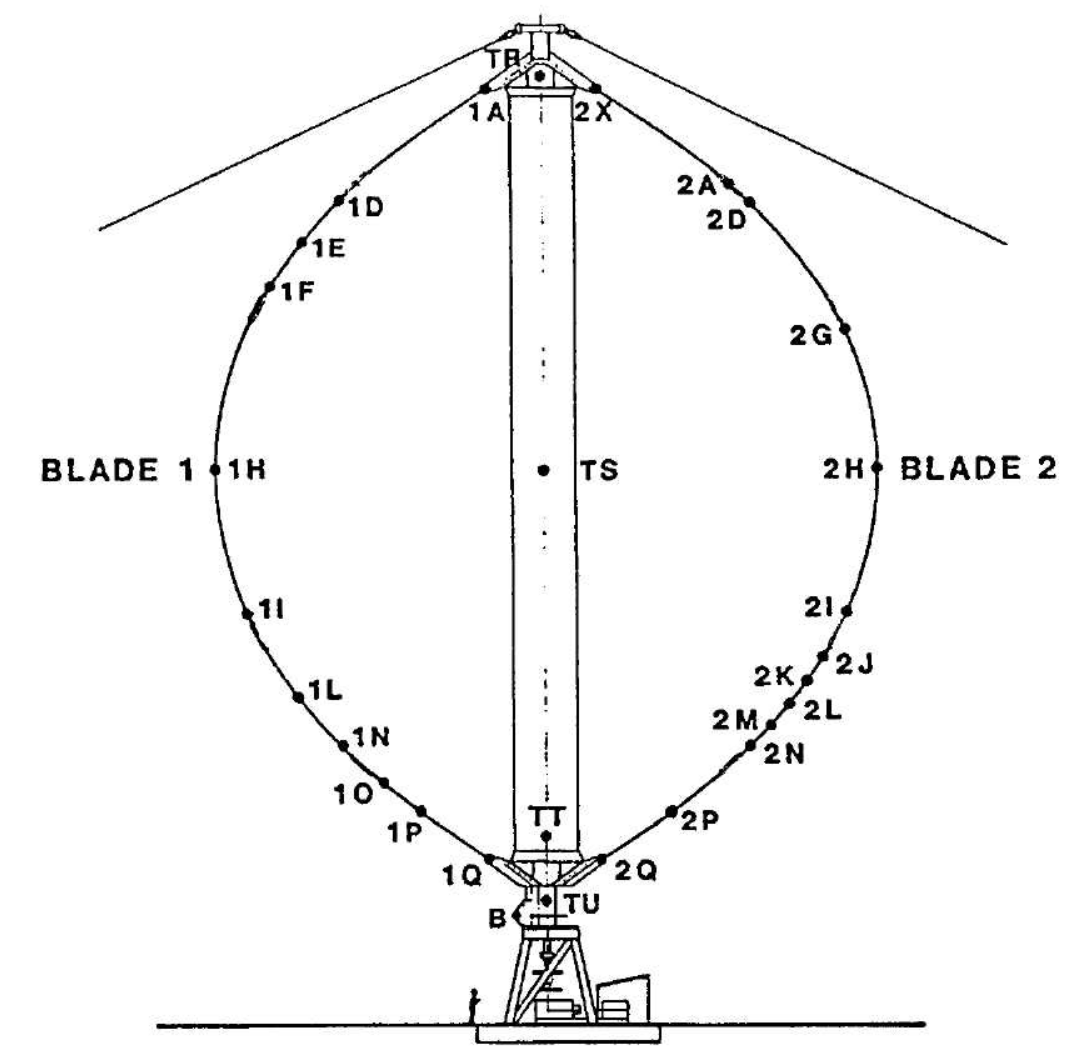

Fig 6. Schematic of DOE/Sandia 34-m Testbed with indicated strain gauge

locations.

.
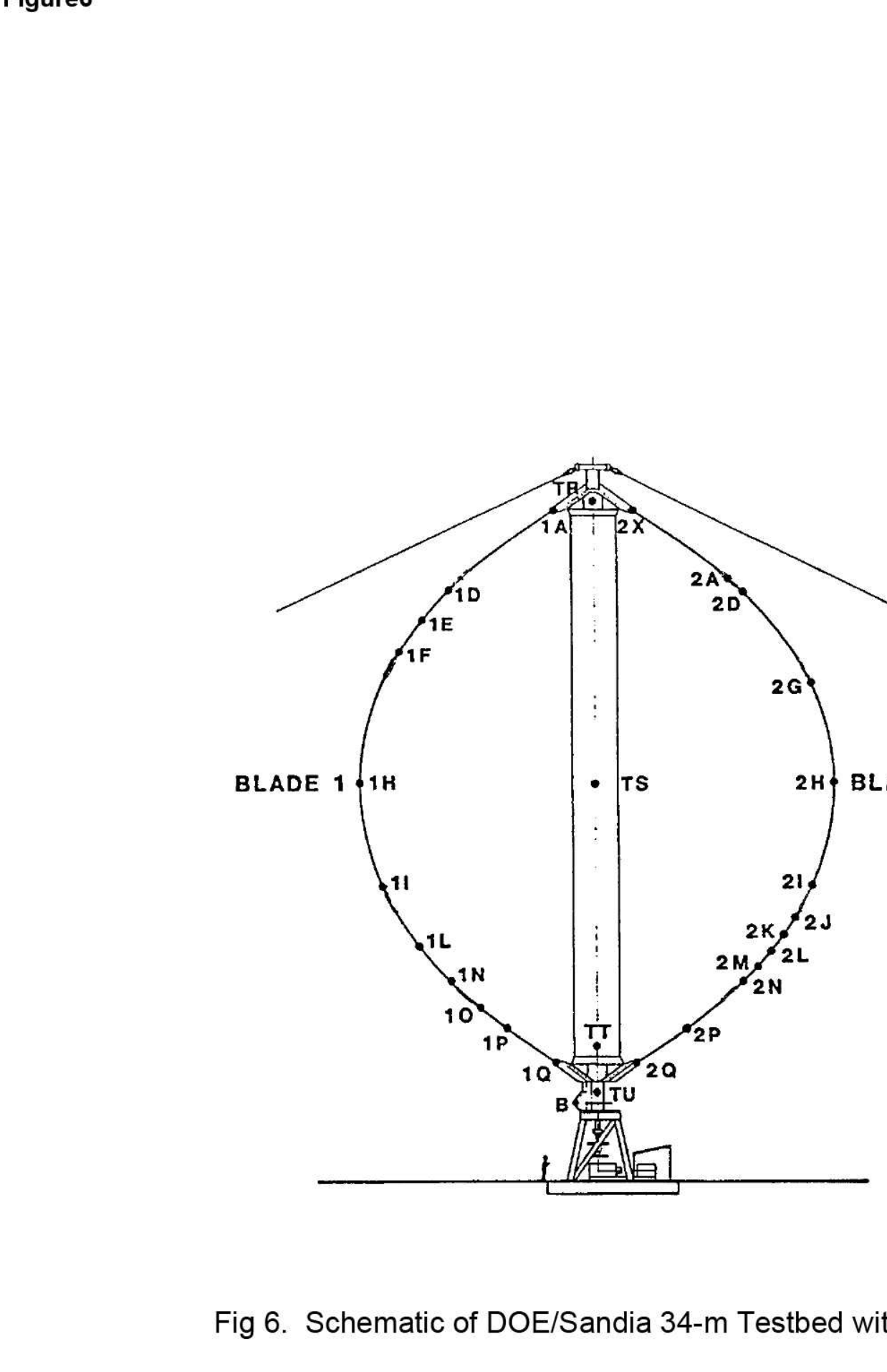

\section{(ic}

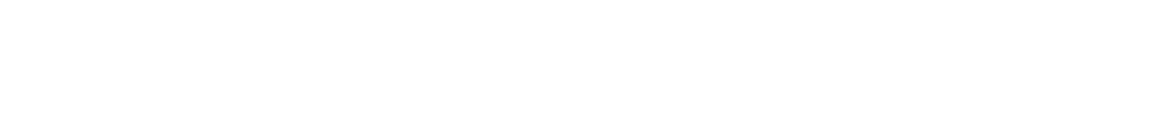

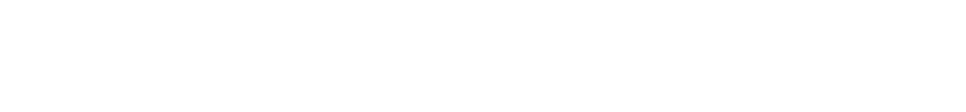

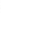

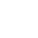




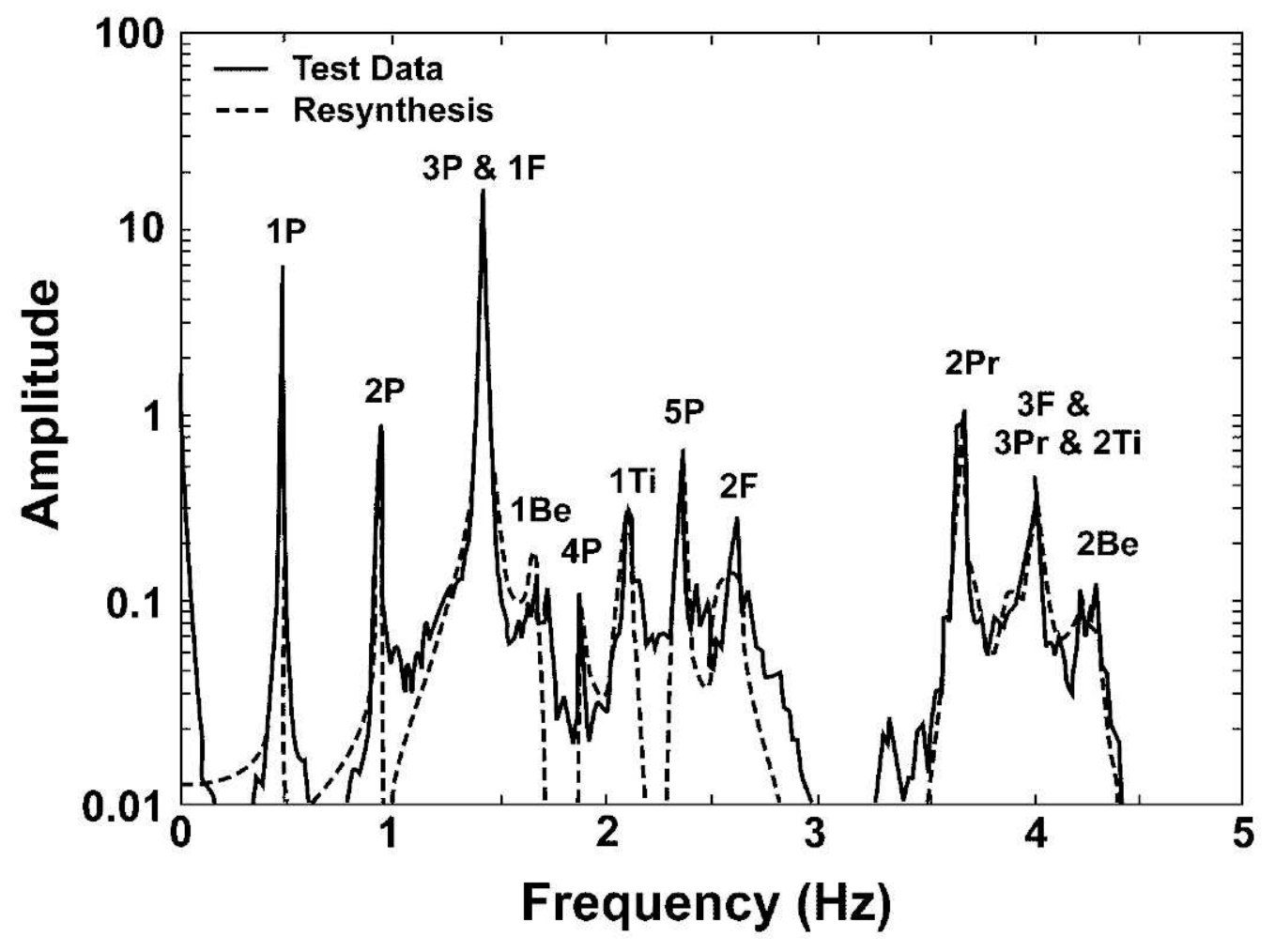

Fig 7. Measured and synthesized auto-spectra of blade edgewise strain at $28 \mathrm{rpm}$ 


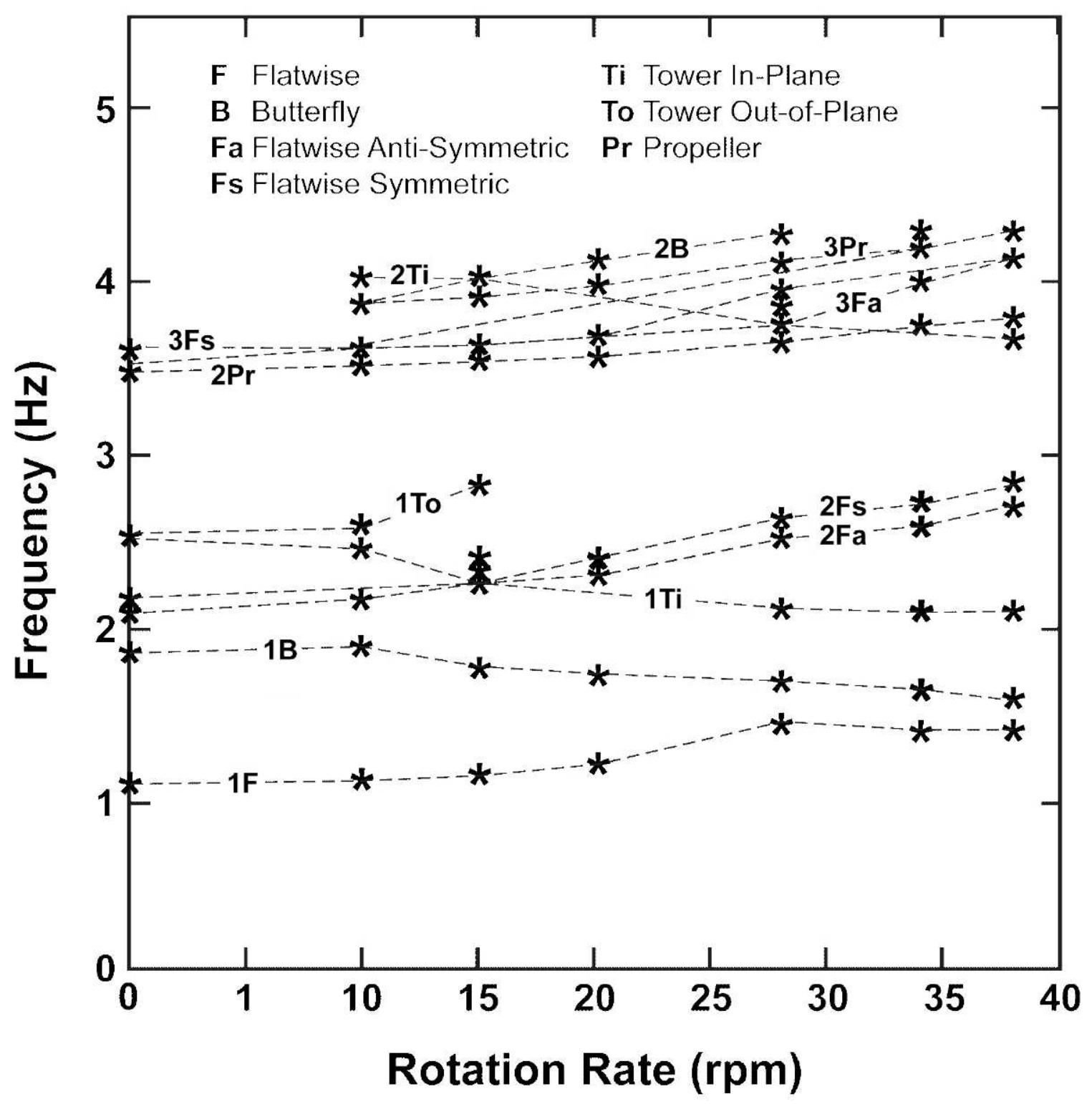

Fig 8. Measured modal frequencies as a function of rotation rate for the 34-m Testbed turbine. 


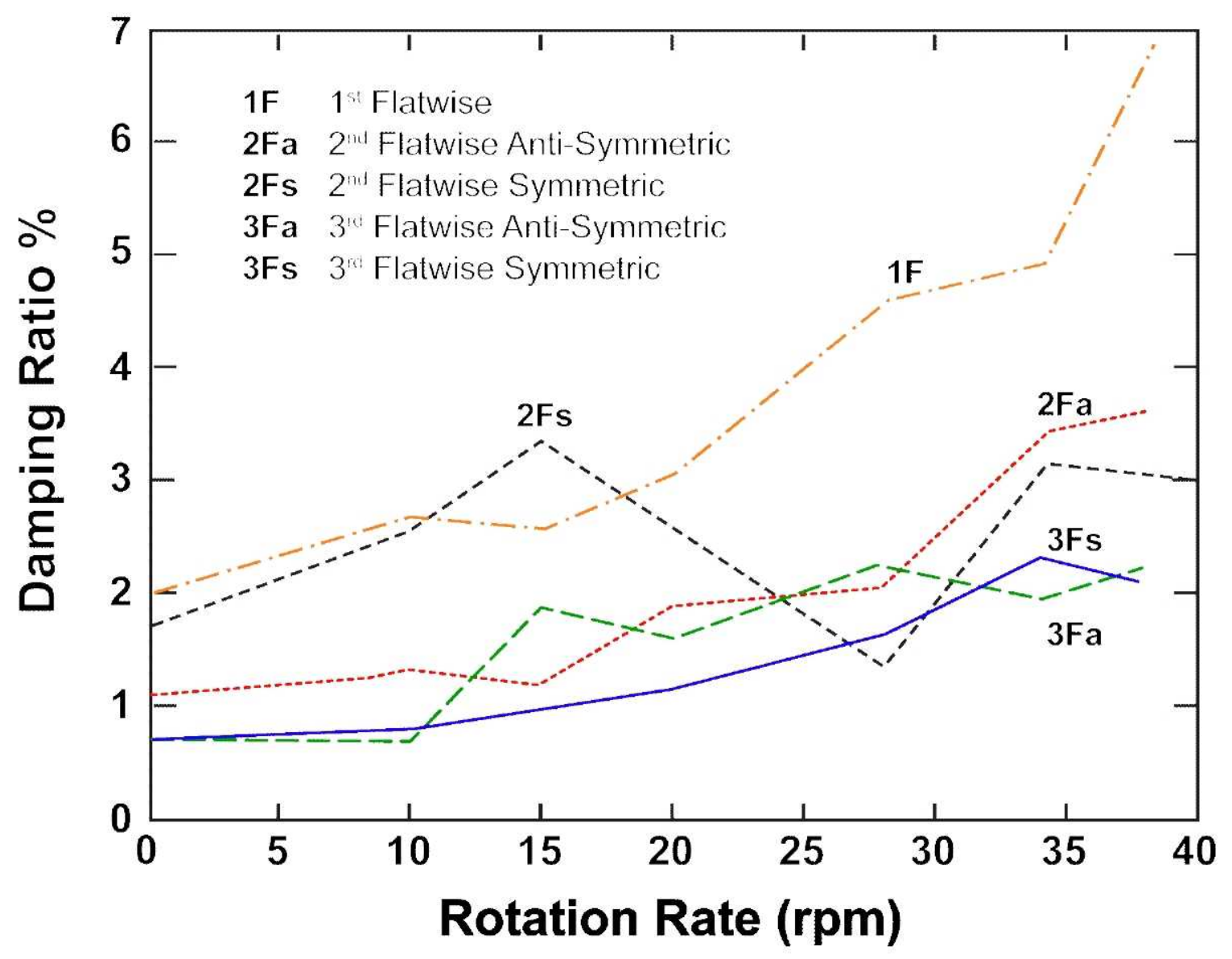

Fig 9. Damping of the flatwise modes as a function of rotation rate for DOE/Sandia 34-m Testbed 


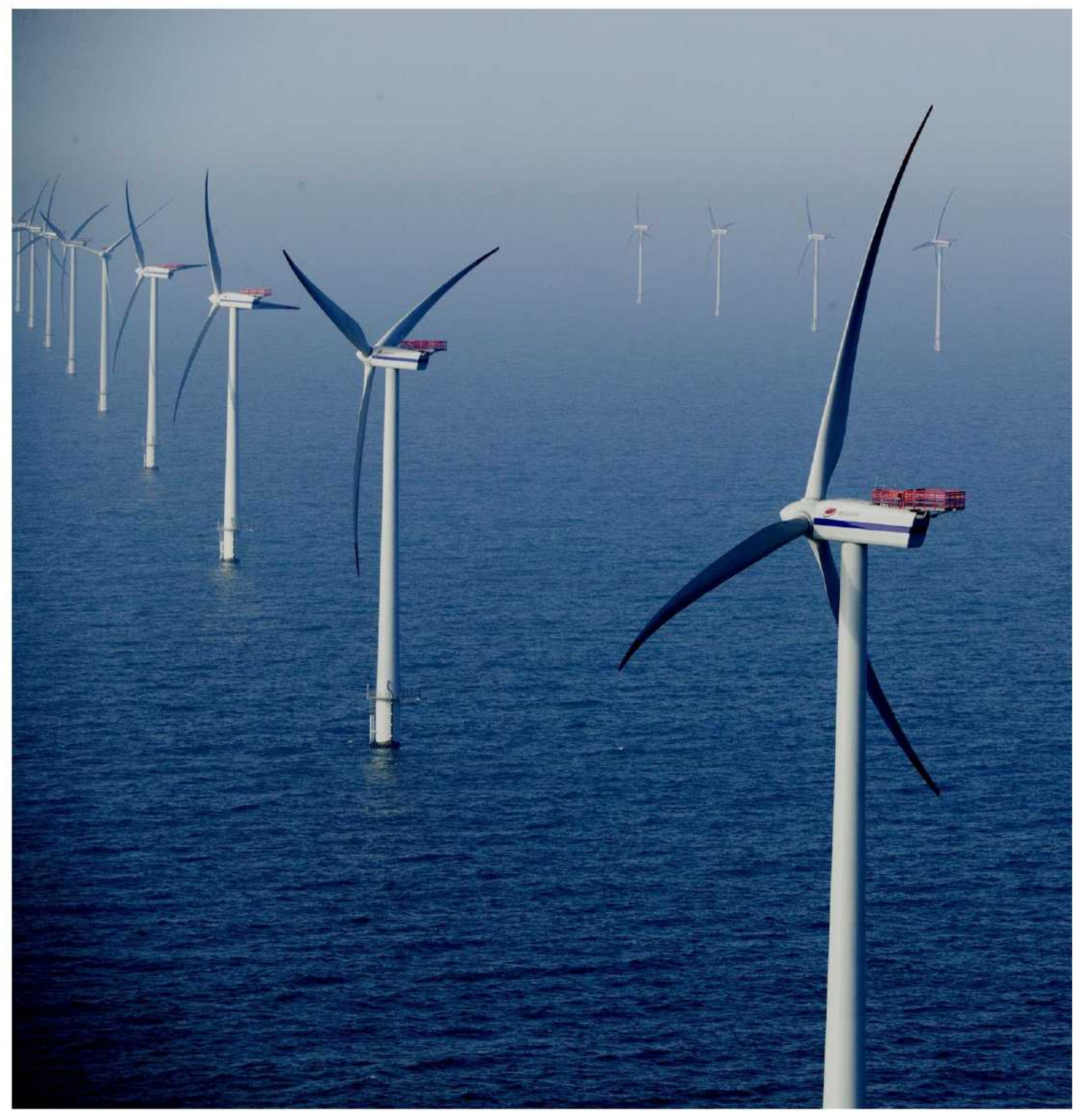

Fig 10. A field of modern Horizontal Axis Wind Turbines offshore in Denmark 


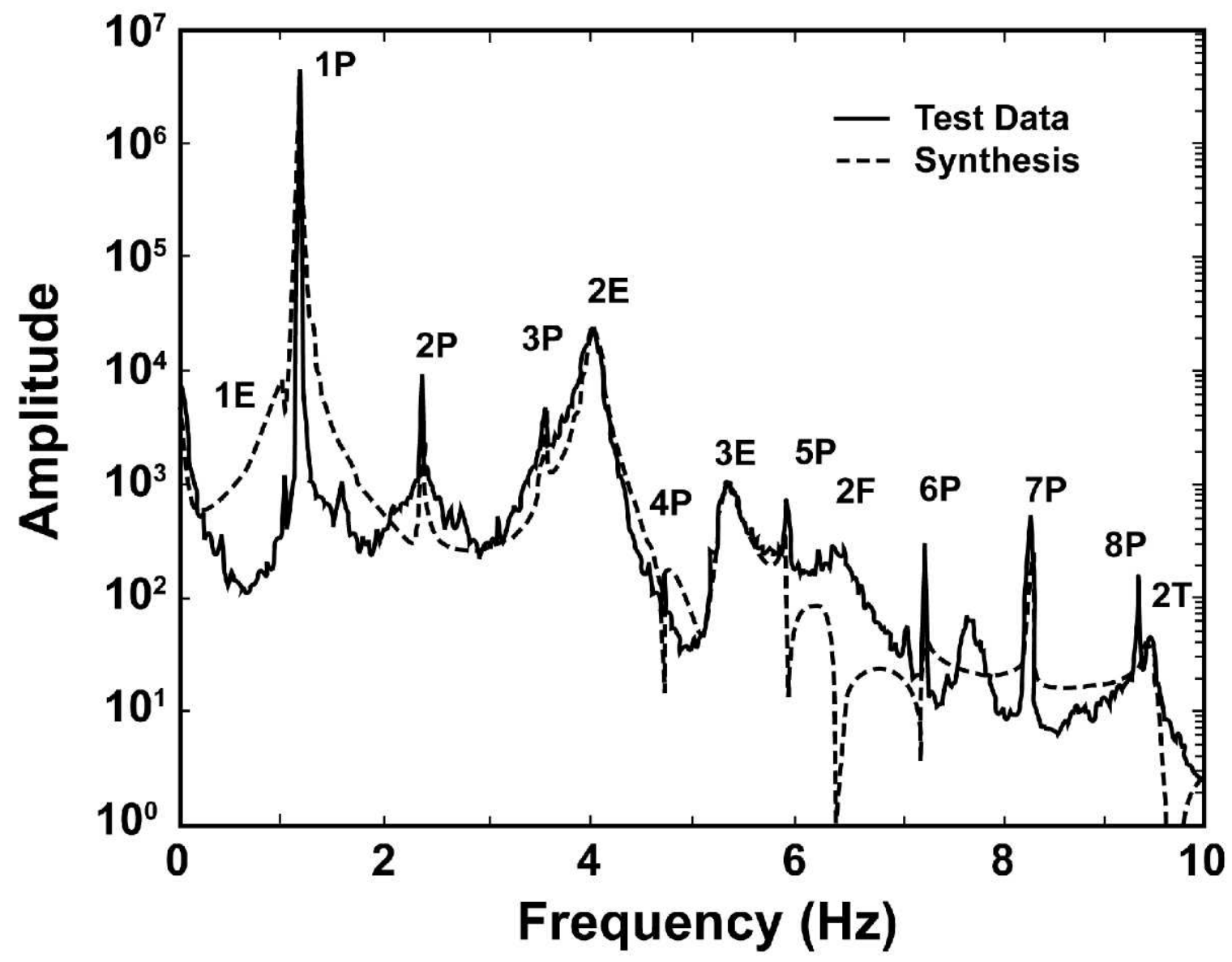

Fig 11. A comparison of the auto-spectra from measured data and the synthesis using the NExT extracted modal parameters 
Table 1

Comparison of modal frequencies using step-relaxation and wind-excitation

\begin{tabular}{|l|c|c|}
\hline MODE SHAPE DESCRIPTION & $\begin{array}{c}\text { STEP RELAXATION } \\
(\mathrm{Hz})\end{array}$ & $\begin{array}{c}\text { WIND EXCITATION } \\
(\mathrm{Hz})\end{array}$ \\
\hline First Tower Out-of-Plane & 0.63 & 0.63 \\
\hline First Tower In-Plane & 0.74 & 0.73 \\
\hline Second Tower Out-of Plane & 0.93 & 0.94 \\
\hline Blade Flatwise Anti-Symmetric & 1.30 & 1.30 \\
\hline Blade Flatwise Symmetric & 1.32 & 1.34 \\
\hline Second Tower In-Plane & 1.38 & 1.39 \\
\hline Blades Bending Out-of-Plane & 1.55 & 1.55 \\
\hline Third Tower Out-of-Plane & 1.79 & - \\
\hline Rotor Twist (Dumbbell) & 1.93 & 1.94 \\
\hline Second Flatwise Symmetric & 2.24 & 2.25 \\
\hline Second Blade Out-of-Plane & 2.33 & 2.33 \\
\hline Second Blade Anti-Symmetric & 2.40 & 2.39 \\
\hline
\end{tabular}


Table 2

Comparison of modal parameters extracted using NExT with the analytical values

\begin{tabular}{|l|c|c|c|c|}
\hline \multirow{2}{*}{ MODE SHAPE DESCRIPTION } & \multicolumn{2}{|c|}{ Frequency (Hz) } & \multicolumn{2}{c|}{ Damping (\%) } \\
\cline { 2 - 5 } & Simulated & NExT & Simulated & NExT \\
\hline First Flatwise Anti-Symmetric & 1.27 & 1.31 & 0.2 & 0.4 \\
\hline First Flatwise Symmetric & 1.35 & 1.32 & 0.2 & 0.3 \\
\hline First Blade Edgewise & 1.59 & 1.59 & 0.3 & 0.3 \\
\hline First Tower In-Plane & 2.02 & 2.01 & 0.3 & 0.4 \\
\hline Second Flatwise Symmetric & 2.43 & 2.44 & 0.4 & 0.5 \\
\hline Second Flatwise Anti-Symmetric & 2.50 & 2.50 & 0.4 & 0.4 \\
\hline First Tower Out-of-Plane & 2.80 & 2.80 & 0.3 & 0.5 \\
\hline Second Rotor Twist & 3.39 & 3.39 & 0.5 & 0.6 \\
\hline Second Tower In-Plane & 3.46 & 3.45 & 0.5 & 0.4 \\
\hline Third Flatwise Anti-Symmetric & 3.65 & 3.63 & 0.5 & 0.4 \\
\hline Third Flatwise Symmetric & 3.73 & 3.73 & 0.6 & 0.4 \\
\hline Second Blade Edgewise & 3.88 & 3.87 & 0.5 & 0.3 \\
\hline
\end{tabular}


Table 3

Comparison of modal frequencies and damping values computed with NExT and traditional techniques

\begin{tabular}{|l|c|c|c|c|}
\hline \multirow{2}{*}{ MODE SHAPE DESCRIPTION } & \multicolumn{2}{|c|}{ Frequency (Hz) } & \multicolumn{2}{c|}{ Damping (\%) } \\
\cline { 2 - 5 } & $\begin{array}{c}\text { Step- } \\
\text { Relaxation }\end{array}$ & NExT & $\begin{array}{c}\text { Step- } \\
\text { Relaxation }\end{array}$ & NExT \\
\hline First Rotor Twist & 2.37 & 2.38 & 0.2 & 0.1 \\
\hline First Flatwise Anti-Symm. & 2.48 & 2.49 & 0.2 & 1.3 \\
\hline First Flatwise Symmetric & 2.51 & 2.51 & 0.1 & 1.4 \\
\hline First Tower Out-of-Plane & 2.72 & 2.76 & 0.4 & 0.4 \\
\hline First Tower In-Plane & 3.11 & 3.15 & 0.4 & 0.4 \\
\hline Second Tower Out-of-Plane & 4.53 & 4.53 & 0.1 & 0.1 \\
\hline Second Flatwise Anti-Symm. & 5.30 & 5.31 & 0.3 & 0.8 \\
\hline Second Flatwise Symmetric & 5.64 & 5.65 & 0.1 & 0.6 \\
\hline Second Rotor Twist & 6.59 & 6.62 & 0.1 & 0.1 \\
\hline Second Tower In-Plane & 6.64 & 6.71 & 0.3 & 0.6 \\
\hline
\end{tabular}


Table 4

Frequencies (modes and rotation harmonics) and damping values for a HAWT in $9 \mathrm{~m} / \mathrm{s}$ winds

\begin{tabular}{|c|c|c|}
\hline $\begin{array}{c}\text { MODE SHAPE } \\
\text { or HARMONIC }\end{array}$ & Frequency (Hz) & Damping (\%) \\
\hline Teeter & 1.04 & 3.2 \\
\hline First Harmonic & 1.18 & .1 (apparent) \\
\hline Second Harmonic & 2.37 & .3 (apparent) \\
\hline Third Harmonic & 3.56 & .5 (apparent) \\
\hline Edgewise & 4.06 & 1.9 \\
\hline Fourth Harmonic & 4.75 & .5 (apparent) \\
\hline Edgewise & 5.34 & 1.5 \\
\hline Fifth Harmonic & 5.94 & .3 (apparent) \\
\hline Second Flapwise & 6.37 & 1.2 \\
\hline Sixth Harmonic & 7.28 & .3 (apparent) \\
\hline Seventh Harmonic & 8.33 & .2 (apparent) \\
\hline Eighth Harmonic & 9.38 & .1 (apparent) \\
\hline Second Tower & 9.52 & 1.1 \\
\hline
\end{tabular}

